\title{
Aproximación al discurso episcopal en torno a la familia (el Concilio Vaticano II, $y$ al episcopado latinoamericano $y$
} mexicano)

\author{
Miguel G. Rodríguez Lozano
}

IIP-UNAM

Se parte de la idea de que existe una pluralidad discursiva en el interior de la Iglesia católica, la cual necesita ser estudiada para comprender, en lo posible, cómo funcionan las propuestas de dicha institución. A partir de ahí, se ensaya un breve acercamiento al concepto de familia planteado en el discurso episcopal de algunos documentos, durante y poco después del Concilio Vaticano II.

\section{INTRODUCCIÓN}

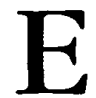

1 historiador que se dedica a la historia y la teoría de las religiones se enfrenta, de entrada, a un problema básico en la aproximación interpretativa, ya que, a diferencia de otros campos de estudio, la religión, cualquiera que ésta sea, llámese shintoísmo, confucianismo, jainismo, judaísmo o cristianismo, por mencionar sólo algunas, presenta más agudamente la dificultad de discernir entre lo objetivo y lo subjetivo, ya que la experiencia individual de los historiadores concernidos frente al hecho re- ligioso puede determinar su manera de percibir el fenómeno.

Así, la interpretación también es afectada cuando el historiador sólo historia las instituciones religiosas y, en un proceso de larga duración, sitúa el cuándo, el dónde y el por qué surge una religión $\mathrm{X}$, olvidando que, al analizarla e interpretarla, necesita de otros corpus teóricos -de diferente área- para hacerlo. Es decir, el historiador debería utilizar la filosofía, la psicología, la antropología, la sociología y, alrededor de éstas, el estructuralismo, el comparativismo, el funcionalismo, el relativismo cultural u 
otros referentes más, con acentos diversos. Únicamente a partir de estos parámetros, el historiador podría acercarse al fenómeno religioso y estudiarlo.

Ahora bien, si eso es viable en muchas de las religiones, en el caso de la religión católica se complica el asunto en cuanto a que, alrededor de ella, se ha formado una institución político-administrativa ideológica, pertrechada en sí misma, que hace difícil que el historiador salga de la historia en sí para crear, entonces, una ciencia de las religiones que, "yendo hasta lo más profundo de las estructuras del fenómeno religioso, definirá el papel y la función de los mitos y los símbolos".

Evidentemente no se trata de ne. gar la importancia de la historia de las religiones y, concretamente, de la Iglesia católica como institución, historia que es básica para tener líneas espacio-temporales que permitan al historiador moverse conceptualmente; no obstante, un estudio no puede quedarse ahí, debe ir más allá de esos lineamientos.

En el caso de la Iglesia católica en México se ha caído en el extremo de historiar el fenómeno aislándolo a veces de los sujetos practicantes, quienes son, dada su socialización, los que determinan y dan fuerza o debilitan a una religión. Ese poder y esa fuerza de lo religioso en los procesos sociales puede atenderse mejor partiendo del sujeto creyente, y no sólo de la dinámica de las institucio-

\footnotetext{
${ }^{1}$ Meslin, Aproximación, 1978, p. 20.
}

nes y de sus protagonistas. ${ }^{2}$ En sí, yo tomo el hecho religioso como "un conjunto dinámico de representaciones simbólicas, creencias y prácticas consecuentes y de la organización jerarquizada de sus agentes". ${ }^{3}$

Desde lo aquí planteado, surge la necesidad de historiar, analizar e interpretar de otra forma las fuentes que se tienen, de manera que el fenómeno pueda verse desde otras perspectivas. ${ }^{4}$ Así, el siguiente trabajo es un intento de analizar brevemente los discursos episcopales referidos a la familia en algunos documentos del Concilio Vaticano II (1962), en la Segunda Conferencia General del Episcopado Latinoamericano (1968) y en una declaración de obispos mexicanos sobre el tema (Mensaje del episcopado al pueblo de México sobre la paternidad responsable, 1972). Además, se ponen a la consideración del lector algunas categorías metodológicas que sirven para distinguir el tipo de discurso a analizar con el fin de realizar un acercamiento a un discurso específico: el episcopal. En ese sentido, no es mi intención reflexionar sobre el concepto de familia en cada una de las categorías establecidas; por el contrario, se trata de una propuesta que permite ubicar bien el discurso en que centro mi análisis aproximativo como otra manera de

\footnotetext{
${ }^{2}$ Un ejemplo de la historia oficial de la Iglesia católica es el libro de Gutiérrez, Historia, 1993. Un estudio desde la perspectiva de los creyentes es el de Masferrer, "Nuevos", 1991, pp. 43-56.

${ }^{3}$ Guzmán, "Relaciones", 1990, p. 5

${ }^{4}$ Véase Puente (comp.), Hacia, 1993 y Blancarte, Historia, 1993.
} 
mirar lo concerniente a la religión católica, pero sin perderla de vista como un todo.

Finalmente, sé que el acercamiento que aquí elaboro es limitado, pero parto de la idea de que, para analizar e interpretar el fenómeno religioso católico desde sus actores, los creyentes, que es lo que me interesa a futuro, se requiere del conocimiento previo del discurso episcopal, a partir del cual el historiador puede visualizar el significado de las prácticas concretas en el interior de la Iglesia católica, como primer paso para reconocer, con mayor visión, el resto de las categorías.

\section{EL APARATO CONCEPTUAL: LAS CATEGORÍAS}

Como institución, la Iglesia católica ha creado a lo largo de su historia varios discursos que la sustentan y la confirman ante la sociedad. Son discursos que, escritos o no, conforman una idea del mundo, y es más, una idea de la sociedad en que se están desarrollando.

Si bien existen varias definiciones de discurso, para mí, y siguiendo a Benveniste, el discurso "es lenguaje puesto en acción"; ${ }^{5}$ de otra manera, coincido en que "todo aquello que ha producido un texto [...] lo que suscita [...] se articula en un objeto integrado cuyo momento material lo denominamos 'discurso'" ${ }^{6}$ En este sentido considero un discurso escrito y uno

\footnotetext{
${ }^{5}$ Benveniste, Problemas, 1985, t. I, p. 179.

${ }^{6}$ Jitrik, Balcón, 1988, pp. 148-149.
}

no escrito, a partir de los cuales se pueden elaborar categorías no autónomas, más bien relacionadas entre sí, que funcionen de manera práctica para la interpretación de los discursos. $^{7}$

\section{El discurso escrito}

Para este discurso he conformado cinco categorías, las cuales se vinculan con actores institucionales y no institucionales. Hablo aquí del discurso bíblico, episcopal, histórico-eclesial, disidente y complaciente.

El discurso bíblico. Quizá por ser éste el discurso más obvio en la religión cristiana, se deja de lado su cometido; sin embargo, todo discurso, escrito o no, desarrollado en la institución católica, parte de ese "gran código"8 que sustenta al resto de los dis-

${ }^{7}$ Cabe aclarar que la preocupación por el análisis de los discursos producidos por la Iglesia no es nueva. Enrique Marroquín, por mencionar un autor que conozco, en su ensayo "El discurso religioso" propone categorías de análisis que lamentablemente son poco prácticas. Él habla de once categorías: el discurso místico, el discurso devocional, la homilía, el discurso teológico, el discurso mítico, el discurso apologético proselitista, el cliscurso doctrinal, el discurso de catequesis, el discurso del lenguaje ritual, el discurso moral y lo que se encuentra "fuera del campo verbal". No sólo eso, parte de un análisis demasiado encasillado en la lingüística. No obstante, hay categorías que pueden utilizarse, como es el caso de la homilía, que tiene que ver con "los sermonarios". Esta constituye el "tipo más adecuado para la transmisión ideológica" (p. 51), de ahí su importancia.

${ }^{B}$ Este concepto está tomado de Northrop Frye, quien estudia la Biblia desde un punto de vista más bien literario; no obstante, la idea 


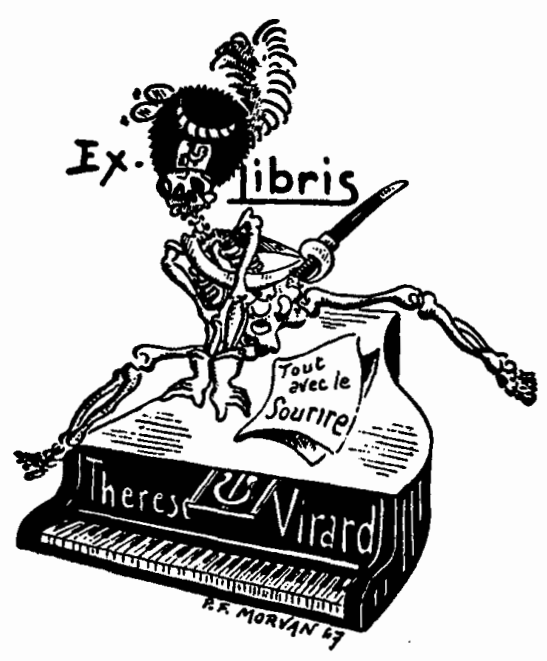

cursos y que es la base fundamental de que se parte para justificar cualquier acción de la Iglesia. Así, este discurso se encuentra por todas partes como fundamentación:

En la aurora de la salvación, el nacimiento de un niño es proclamado como una gozosa noticia: "Os anuncio una gran alegría, que lo será para todo el pueblo; os ha nacido hoy, en la ciudad de David, un salvador, que es el Cristo Señor" ( $L C$ 2, 10-11). El nacimiento del Salvador produce ciertamente esta "gran alegría"; pero la $\mathrm{Na}$ vidad pone también de manifiesto el

del "gran código", que proviene del poeta William Blake, resulta atractiva por la función que cumple la Biblia no sólo en los estudios literarios, sino también dentro de los discursos producidos por la Iglesia como institución. sentido profundo de todo nacimiento humano, y la alegría mesiánica constituye así el fundamento y la realización de la alegría por cada niño que nace (véase $J n 16,21$ ).

Presentando el núcleo central de su misión redentora, Jesús dice: "Yo he venido para que tengan vida y la tengan en abundancia" ( $n$ 10, 10).

Pero escuchad también de nuestros labios, hermanos, vosotros -personalmente más fuertes y más valientes que Nos mismo-, la palabra de Jesús, con la cual Él, presentándose entre las olas borrascosas, en una noche llena de peligros, gritó a sus discípulos que navegaban: "Soy yo, no temáis." Sí, Nos queremos repetiros esa exhortación del Maestro: "No temáis." Ésta es para la Iglesia una hora de ánimo y de confianza en el Señor. ${ }^{10}$

El discurso bíblico tiene una gran influencia sobre el discurso episcopal. No podía ser de otro modo, ya que las grandes religiones monoteístas (judaísmo, cristianismo c islamismo) basan sus experiencias religiosas en algún texto para avalar su doctrina. Ambos son la base de que parte el resto de las producciones discursivas.

El discurso episcopal. Es el discurso oficial que emana de las institu. ciones eclesiales y tiene su soporte en el discurso bíblico, aunque éste no siempre aparece de manera textual. Las declaraciones del papa, los obispos, arzobispos, etc., por cualquier medio impreso, entran dentro de este tipo de discurso. Las cartas papales, las encíclicas y todo documento insti-

\footnotetext{
'Juan Pablo II, Evangelio, 1995, p. 3. p. 17.
} 
tucional dirigido a ganar adeptos, a mostrar la filosofía de la religión, se ubican en este rubro. Un ejemplo, entre muchos otros, es el siguiente:

La religión se suele considerar por los técnicos del desarrollo como un factor fundamental que puede ayudarlo u obstaculizarlo. La religión cristiana no es el desarrollo, pero sí es, entendida en su fundamentación y proyección auténtica, [como] la motivación más honda que pueda encontrarse -al menos para los cristianos- para el desarrollo y la integración. ${ }^{11}$

Tanto este discurso como el bíblico van a convertirse en la parte sustancial del resto de los discursos, pues es a partir de estos dos que se clesarrollarán las diversas tendencias discursivas. De ahí la necesidad de adentrarse primero en ese discurso para el estudio del fenómeno religioso en la vertiente católica.

El discurso bistórico eclesial. En esta categoría entrarían todos los estudios alrededor de la Iglesia, tanto los particulares, dedicados a trabajar sólo un aspecto, como los generales: las historias de la Iglesia, por ejemplo. Considerando esto, habría aquí, a su vez, dos tipos de discurso: el histórico eclesial tradicional y el histórico eclesial crítico. El primero se distingue por tener, en algunos momentos, una visión totalmente historicista y apegada a la norma oficial, es decir, apoyada en la fe; el segundo parte de elementos teóricos y de perspectivas más objetivas. Un texto clásico para ejemplificar el primer caso es el de

\footnotetext{
${ }^{1}$ Conferencia, Documentos, 1991, p. 84.
}

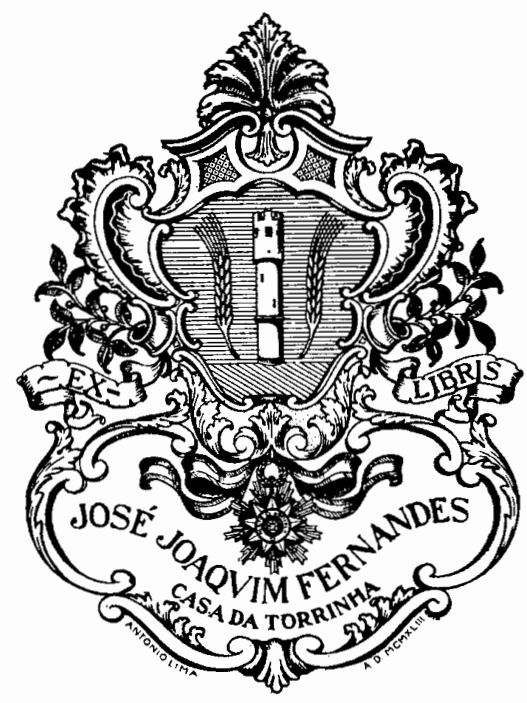

Gutiérrez Casillas, quien pone en evidencia su posición frente al objeto de estudio al analizar los hechos históricos según los intereses de la Iglesia como institución:

El primer presidente de esta época de paz, y a quien la historia le reconoce el mérito de haberse dado cuenta de que para gobernar al pueblo de México es necesario no contravenir sus costumbres y aspiraciones, fue el gencral don Manuel Ávila Camacho (1897-1955), del 1 de diciembre de 1940 al 30 de noviembre de 1946. Hombre bueno, que se hizo querer de la nación. Aprovechó las circunstancias $[. .$.$] y formentó$ la unificación en lo político y en lo religioso, gobernando para todos. ${ }^{22}$

${ }^{12}$ Gutiérrez, Historia, 1993, p. 485. 
En el segundo caso son más diversos los textos, dada su pretensión de cientificidad. Entre ellos, podemos citar como muestra los siguientes: El fin de la ambigüedad: las relaciones entre la Iglesia y el Estado en México, 1982-1989, de Soledad Loaeza (1990), Papel y responsabilidad social de los laicos; "Rerum Novarum", derechos bumanos $y$ derechos sociales de María Alicia Puente (1991) y los artículos contenidos en el tomo Iglesia y religiosidad, del cual reproduzco las palabras de Elsa Cecilia Frost ("El milenarismo franciscano en México y el profeta Daniel"), como un ejemplo de un análisis inteligente y nada superficial:

Torquemada toma, a su vez, una especie de camino intermedio. Niega que haya habido una predicación anterior y acepta que España ha sido elegida por Dios para evangelizar estas tierras; pero, en cierta forma, se desvía del problema y toda su obra resulta un inten. to por demostrar que, si bien estas gentes no tuvieron jamás contacto con el mundo conocido $[. .$.$] y eran tan ig-$ norados por la cristiandad como ignorantes de ella, nada impide que, una vez descubiertos providencialmente, lleguen a ocupar su puesto dentro de la ecumene cristiana. A base de una erudición bíblica y clásica que parece inagotable, fray Juan va trazando el paralelo entre los indios y los pueblos de la antigüedad a fin de demostrar qué tan capaces fueron unos como otros de construir una gran cultura. ${ }^{13}$

Existen, por supuesto, más ensayos esclarecedores que no he menciona-

${ }^{13}$ Iglesia, 1992, p. 73. do, pero que considero están dentro de un discurso crítico. ${ }^{14}$

El discurso disidente. En esta categoría ubico, evidentemente, a la Teología de la Liberación que, como se sabe, sin echar a un lado los dos primeros discursos, presenta divergen. cias que la alejan, por momentos, del dogma institucional. "Para los teólogos de la liberación, la historia aparece como un proceso de liberación. Consideran que el hombre ha de tomar en sus manos su destino por medio de los cambios que le son posibles." 15

Es tan importante esta tendencia que llega a filtrarse en el discurso episcopal; no podía ser de otra manera, ya que formó parte de las diferentes vertientes surgidas después del Concilio Vaticano II, gracias al cual hubo un desarrollo cristiano-católico que permitió un contacto más estrecho con el pueblo y, por ende, con la realidad social. La Teología de la Liberación tiene, incluso, su propia historiografía. Sin duda, el mejor ejemplo de lo producido en este rubro discursivo se encuentra en la Historia de la Iglesia en América Latina del Cenila (Comisión de Estudios de Historia de la Iglesia en América Latina), ya que, como lo plantea Enrique Dussel:

Se entiende teológicamente la historia de la Iglesia en América Latina como la historia de la institución sacramental de comunión, de misión, de conversión como palabra profética que juzga

${ }^{14}$ Algunos ejemplos pueden verse en la bibliografía final.

${ }^{15}$ Cervantes, Teologia, 1989, p. 21. 
y salva, como la Iglesia de los pobres. Aunque todos estos aspectos son expresiones vivas de un solo cuerpo, nos parece que es más conveniente, por razones evangélicas, históricas y exigencias presentes, prestar especial atención en nuestro enfoque histórico al pobre. Porque en América Latina la Iglesia siempre se ha encontrado ante la tarea de evangelizar a los pobres (el indígena, el negro, el mestizo, el crio1lo, los obreros, los campesinos, el pueblo). ${ }^{16}$

No es el espacio para analizar los límites y alcances de este tipo de discurso, pero es obvio que abrió las puertas al debate y a la polémica. ${ }^{17}$

El discurso complaciente. Es éste el discurso más abundante por su función publicitaria y por el papel ideológico que juega en la conformación de los diferentes discursos desarrollados dentro de la Iglesia. Aquí aparecen las publicaciones que siguen el dogma religioso y las que atacan, por diferentes medios, a otras religiones que no tengan que ver con el catolicismo. Así, encontramos títulos como: Vivir la pobreza cristiana; Receta para un asesinato: el aborto; Mentiras y disparates de los testigos de Jehová; El matrimonio, vocación cristiana; La terapia de Dios; Pastores que abusan; La verdad sobre el

\footnotetext{
${ }^{16}$ Dussel, "Palabras", 1984, p. 11.

${ }^{17}$ Véase para el caso, y como ejemplo, el excelente ensayo de Paulo Suess, "La historia de los Otros escrita por nosotros. Apuntes para una autocrítica de la historiografia del cristianismo en América Latina", en el que se cuestionan algunos conceptos utilizados en la Historia general, del CEHILA.
}

rock cristiano, entre muchos miles. ${ }^{18}$ Ejemplifico con la propaganda de los dos últimos libros citados:

En la última década, la juventud cristiana ha sido cautivada por una nueva corriente musical que ha causado sensación: el rock cristiano.

En este libro, el lector podrá entender las razones y principios bíblicos que demuestran que, lejos de ser una inocente forma de entretenimiento, este tipo de música es destructivo para la salud espiritual de sus adeptos y uno de los más sutiles engaños que Satanás ha lanzado para pervertir a la juventud (La verdad sobre...).

Sectas, falsos profetas, gurús, iluminados y supuestos Mesías, y todos tienen una característica: son autoritarios y saben manipular [...] El objetivo de este libro no es en ningún momento desanimar a nadie en su búsqueda de Dios. Al contrario, nuestro interés es sólo advertir acerca de los peligros de caer en manos de un mal liderazgo cristiano (Pastores...).

Ante este tipo de discurso, urge la necesidad de analizarlo cuidadosamente porque, como quiera que sea, crea un fenómeno que sobrepasa la cuestión ideológica para plantear más bien un asunto moral que puede estar relacionado con el punto de vista de un grupo económico-social específico (Provida, por ejemplo) y, por tanto, esconder otros intereses, éstos sí, ideológicos, políticos, económicos, o de cualquier otra índole.

El discurso no escrito. Los sujetos creyentes son la base del desarrollo y

${ }^{18}$ Sólo pongo unos cuantos títulos que se encuentran a la vista de los lectores en las librerías de México. 
de la significación del discurso no escrito. A diferencia de la clasificación anterior, en éste sólo considero dos aspectos: las ceremonias y los ritos de paso. Ambos se presentan en un espacio sagrado interior o exterior.

En las ceremonias se combinan diferentes discursos y sucede, sobre todo, en las indígenas, donde hay un sincretismo entre los elementos cristianos y los de la cultura indígena de que se trate. Esto se encuentra, por ejemplo, en la danza de los "matachines". En las ceremonias totalmente católicas también hay una mezcla de discursos, sustentados en el bíblico y en el episcopal, vistos anteriormente.

Los ritos de paso son el discurso con más significación, en cuanto que presentan la manera de ver el mundo de la sociedad o comunidad que practica una religión. Como se sabe, estos ritos son importantes para el análisis de las religiones y, en este sentido, el catolicismo no se queda atrás. El rito es la expresión de una experiencia religiosa; la oración y las ofrendas, por ejemplo, son tipos de ritos (como el "Padre nuestro" y el "Credo" en las ceremonias católicas). Los ritos de paso, marcan además una transición hacia un estado en que el sujeto cobra otro distinto que lo distancia, por un momento, de la comunidad. Son ritos de paso en la religión católica el bautismo, la confirmación, la primera comunión, la boda y, por supuesto, el sacramento de la eucaristía: tomar la hostia (el cuerpo de Cristo) y el vino (la sangre de Cristo). ${ }^{19}$

${ }^{19}$ Véase sobre el tema, Leach, Cultura, 1978, pp. 107-128.
Evidentemente, tanto las ceremonias como los ritos de paso cambian de una sociedad a otra a través del tiempo, dependiendo de las circunstancias histórico-sociales. Existen, por ejemplo, diferencias sugerentes en la religión católica practicada antes del Concilio Vaticano II y después de éste. Piénsese en la reacción de los creyentes que participaban en una ceremonia celebrada en latín, al encontrarse después con que se les hablaba en español. Este tipo de cambios tuvo que tener consecuencias que, hasta donde yo sé, no se han estudiado. ${ }^{20}$

Así pues, baste, por el momento, este intento conceptual para elaborar las siguientes líneas, de modo que el lector conozca uno de los tantos aspectos posibles a estudiar en el discurso episcopal.

\section{LA APROXIMACIÓN}

El concepto de familia no está aislado de otros conceptos sugerentes que lo determinan y lo condicionan. La paternidad, la maternidad, la pareja, el matrimonio, el aborto, la sexualidad y hasta la educación forman un corpus que tiene su fundamentación en este concepto. Es por ese motivo que, al hablar de "familia", no lo hago como de un aspecto neutro y autónomo, sino más bien como de algo amplio y,

${ }^{20}$ Por supuesto, aludo solamente al aspecto histórico-social, antropológico, de la ceremonia católica. En otros ámbitos teórico-conceptuales, como en el de la psicología, hay aproximaciones muy sugerentes, por ejemplo, la de Carl G. Jung, "El simbolismo de la transformación en la misa", Psicología, 1992, pp. 52-128. 
de entrada, difícil, dado que conforma un eje, a partir del cual se desarrollan las diferentes características de la sociedad: forma de vestir, de actuar, de pensar, etcétera.

Así, cuando hablo de familia estoy haciendo referencia implícita a los aspectos del corpus; y no sólo eso, estoy considerando una idea de familia sustentada en un sistema económico-social específico: el capitalismo. Es evidente que este concepto de familia tiene que ver también con la lucha de clases social y con la supremacía de una clase social burguesa económicamente dominante y apoyada por el Estado, la cual impone formas de vida y de pensamiento. Esto ya lo planteaba bien Engels:

Como el Estado nació de la necesidad de refrenar los antagonismos de clase y como, al mismo tiempo, nació en medio del conflicto de esas clases, es, por regla general, un Estado formado por la clase más poderosa, la económicamente dominante, la cual, con ayuda de éste, se convierte en esa clase políticamente dominante, adquiriendo con ello nuevos medios para la represión y la explotación de la clase oprimida. ${ }^{21}$

En ese caso, la familia, en tanto que unidad económica, está entretejida en las redes del poder que conforma esta sociedad en ese microespacio; por eso para la Iglesia es tan importante ofrecer sus puntos de vista al respecto.

Tanto en el discurso bíblico como en el complaciente, la familia ha sido un punto importante de reflexión. Todo discurso escrito alude, de dife-

${ }^{21}$ Engels, "Origen", 1986, t. III, p. 346. rentes maneras, a la problemática de los elementos que conforman el núcleo familiar. Incluso el discurso no escrito responde también a acciones ligadas íntimamente con la familia: las festividades religiosas en torno al matrimonio son muestra de ello. Dada la estrecha relación entre religión y familia, ésta aparece continuamente en el tejido de los discursos de la Iglesia, ya sea de manera abstracta o como su práctica relacionada con un tipo de sociedad, como sucede en los documentos posteriores al Concilio Vaticano II.

El discurso bíblico tiene, como centro de reflexión, la familia; sobre todo en lo que se relaciona con la procreación ("La herencia del Señor son los hijos, recompensa el fruto de las entrañas", se dice en el Salmo 127). No obstante, el discurso episcopal adecua la conceptualización bíblica de la familia a las circunstancias, aunque esto no signifique que la Iglesia comparta los cambios histórico-sociales de una sociedad. $^{22}$

\footnotetext{
${ }^{22}$ Por supuesto, la adecuación no siempre sucede. Esto se nota, por ejemplo, en una de las últimas encíclicas de Juan Pablo II (El evangelio de la vida), en la cual se anota sobre el aborto lo siguiente: "[...] se trata de señalar todas las consecuencias de este mismo Evangelio, que se pueden resumir así: la vida humana, don precioso de Dios, es sagrada e inviolable, y por esto, en particular, son absolutamente inaceptables el aborto procurado y la eutanasia; la vida del hombre no sólo no debe ser suprimida, sino que debe ser protegida con todo cuidado amoroso; la vida encuentra su sentido en el amor recibido $y$ dado, en cuyo horizonte hallan su plena verdad la sexualidad y la procreación humana; en este amor incluso el sufrimiento $y$ la muerte tienen un sentido $y$, aun permaneciendo el misterio
} 


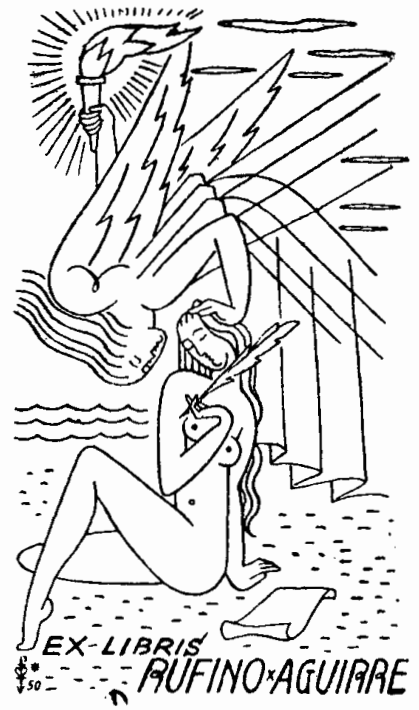

El concepto de familia del que parten los discursos episcopales del Vaticano es abstracto y general, con un tono donde se percibe que la Iglesia no contradice el concepto capitalista. No obstante, la familia crea sus propias reglas dentro del mismo capitalismo, un aspecto que la Iglesia como institución pierde de vista, pero controlando esto, hasta cierto punto, con el discurso complaciente en tanto que éste intenta llegar a las masas.

El problema es que el concepto de familia, tal y como lo maneja la institución Iglesia, se reduce a una cuestión a resolver por la elite, cuando la familia concreta reclama una estabi-

que los envuelve, pueden llegar a ser acontecimientos de salvación [...]" Juan Pablo II, Evangelio, 1995, pp. 147-148). lidad económica y social que, en el caso de los países latinoamericanos, no existe. La Iglesia católica, como institución hegemónica, forma parte del sistema capitalista que por lo mismo la ha apoyado; por ello, no extraña encontrar en ella declaraciones que albergan un control absoluto de las relaciones humanas. ${ }^{23}$

\section{Documentos del Concilio Vaticano II}

Una lectura de los textos dedicados a la familia en este concilio, descubre un discurso que, obviamente, sigue el dogma; pero que, pese a ello, no es nada autoritario, a tal grado que pareciera separarse del dogma institucional cuando se anota:

El matrimonio no es solamente para la procreación, sino que la naturaleza del vínculo indisoluble entre las personas y el bien cle la prole, requieren que el amor mutuo de los esposos mismos se manifieste ordenadamente, progrese y vaya madurando. Por eso, si la descendencia, tan deseada a veces, faltare, sigue en pie el matrimonio como intimidad y participación de la vida toda y conserva su valor fundamental y su indisolubilidad. ${ }^{24}$

${ }^{23}$ Recuérdese que en la historia de la Iglesia siempre se ha exaltado la función reproductora de la familia, entre otras cosas (véase, por ejemplo, para el caso novohispano mexicano Gonzalbo, "Busca", 1996). Sin embargo, también con el tiempo, dicha actitud se ha ajustado por momentos y en ciertos lugares a una realidad histórico-social, aunque ha sido en forma esporádica.

${ }^{24}$ Concilio Vaticano II, Documentos, 1995 , p. 180 . 
En afirmaciones como ésta, hay una socialización de los sujetos creyentes, pues no se les obliga a la procreación. No obstante, es importante notar que, a partir del Concilio Vaticano II, el punto central desarrollado alrededor del concepto de familia es el aspecto demográfico, el cual, paradójicamente, no afecta a la importancia de la Iglesia como institución ni a sus ideas y su papel dentro del mundo, tal como se describe a continuación:

$\mathrm{Y}$, sin embargo, un hecho muestra bien el vigor y la solidez de la institución matrimonial y familiar: las profundas transformaciones de la sociedad contemporánea que, a pesar de las dificultades a que han dado origen, con muchísima frecuencia manifiestan, de varios modos, la verdadera naturaleza de tal institución. ${ }^{25}$

- En este sentido, la Iglesia católica no quiere perder su hegemonía, por tanto, actualizaría el tono de acuerdo con la época (los años sesenta). La liberación femenina y homosexual, la guerra fría, los movimientos estudiantiles, el auge de las drogas y el nacimiento de la cultura del rock son fenómenos que determinan este cambio de actitud de la Iglesia. Un ejemplo singular lo hallamos en la perspectiva que toma dicha institución frente a la mujer, frente al papel de la mujer en el siglo $\mathrm{Xx}$ :

La activa presencia del padre contribuye sobremanera a la formación de los hijos; pero también debe asegurarse el cuidado de la madre en el hogar, que necesitan principalmente los niños me-

${ }^{25}$ Ibid., p. 176.

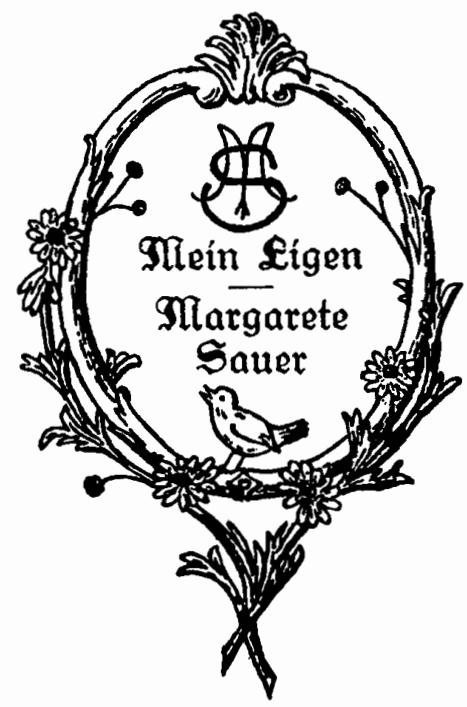

nores, sin dejar, por eso, a un lado la legitima promoción social de la mujer. ${ }^{26}$

Visto desde nuestro presente y a la luz de la encíclica del papa Juan Pablo II ( $E l$ evangelio de la vida), la familia vista por el Concilio Vaticano II se acerca más a la realidad de los pueblos. ${ }^{27}$

\section{Segunda Conferencia General del Episcopado Latinoamericano.}

La cuestión social y el estilo cambian a partir de esta conferencia. No hay

${ }^{26}$ Ibid., p. 181

${ }^{27}$ Hablo de un cambio de actitud de la Iglesia que sólo tuvo su momento en ese Concilio, no de transformación radical, situación que no se ha dado hasta ahora. 
duda de que se produce cierto distanciamiento frente a lo que se había propuesto en el Concilio Vaticano II; ya no se deja de lado la cuestión económico-social de Latinoamérica y sus problemas. De ahí que, en un momento determinado, se diga, adjetivando:

Porque la idea de familia se encarna en realiclades sociológicas sumamente diversas [...] Porque en América Latina la familia sufre de modo especialmente grave las consecuencias de los círculos viciosos del subdesarrollo: malas condiciones de vida y cultura. ${ }^{28}$

Ese reconocimiento de la situación social de América Latina coloca al discurso episcopal en una posición diferente y distante de lo que se dijo en el Concilio Vaticano II; esto posibilitaría también el surgimiento de la Teología de la Liberación que, como discurso disidente, asumiría la opción por las familias pobres. Los creyentes serían vistos entonces como sujetos históricos con problemas reales, no como entes abstractos: "El proceso de desarrollo lleva consigo abundantes riquezas para algunas familias, inseguridad para otras y marginalidad social para las restantes." 29 Entonces, el problema demográfico ya es visto desde otra óptica, mucho más apegada a la realidad social, y no desde una posición estatal, como en el caso de Roma.

$\mathrm{Al}$ asumir la Iglesia la problemática latinoamericana de los años 60 , dio un énfasis diferente a la perspectiva establecida por ella frente a la familia: p. 79 .

${ }^{20}$ Segunda Conferencia, Iglesia, 1968, ${ }^{29}$ Ibid.
El rápido crecimiento, que si bien no clebe ser tomado como la única variable demográfica y mucho menos como la causa de todos los males de América Latina, sí engendra varios problemas, tanto de orden sociocconómico como de orden ético y religioso. ${ }^{30}$

La vinculación sociedad-religión, ya no sólo como teoría sino como práctica, en cuanto que se toma conciencia de las condiciones de vida de un determinado lugar, dio la oportunidad necesaria para redefinir el concepto de familia. En definitiva, cl cpiscopado latinoamericano adecuó su discurso a las condiciones sociales y económicas de América Latina, lo cual fue una ventaja para la Iglesia en un momento (la Segunda Conferencia se realizó seis años después del Concilio) en que la represión por parte del Estado en diferentes países latinoamericanos, no le dejaba opciones. Los totalitarismos ahondaron más la deficiente situación de la familia. Por ello, las ideas del episcopado latinoamericano, por lo menos en el discurso propuesto, resultaban un camino viable.

\section{El episcopado mexicano}

Publicado el 12 de diciembre de 1972, el Mensaje del episcopado al pueblo de México sobre la paternidad responsable es un texto clave para la comprensión de lo que fue el concepto de familia para los obispos mexicanos en los primeros años de la década de los setenta. Visto desde nuestro

${ }^{30} \mathrm{Ibid}$. 
presente, el texto resulta innovador. El episcopado mexicano se enfrenta al problema demográfico de una manera más radical que la Segunda Conferencia, aunque explicitado en un campo social menos amplio: México. Las condiciones estaban dadas, gracias a la crisis política y social proveniente de 1968 y a la crisis económica del momento, además de que había gente que justificaba el discurso propuesto en el documento, por ejemplo, Sergio Méndez Arceo. Así pues, las propuestas tocaban puntos clave de la familia. He aquí ejemplos de algunas ideas trascendentes:

Al fin y al cabo es a los padres a los que les toca decidir con pleno conocimiento de causa, el número de sus hijos, aceptando sus responsabilidades ante Dios, ante los hijos que ya han traído al mundo $y$ ante la comunidad a la que pertenecen, siguiendo las exigencias de su conciencia. ${ }^{31}$

Al igual que las autoridades civiles, o cualquier otra entidad, las autoridades eclesiásticas no pueden suplantar a las parejas y decidir -por ellos- si han de tener muchos hijos, pocos o ninguno, ${ }^{32}$

Dios toma al hombre en su realidad concreta y lo juzga como padre, teniendo en cuenta las circunstancias en que se encuentra: a partir de lo que de hecho sabe, de lo que puede, cle la madurez y cle la capacidad de amor a la que ha llegado. Además, Dios le habla al hombre por sus circunstancias concretas -personales y familiares- de salud, salario, de vivienda, de trabajo, de su capacidad actual de instruir y de

${ }^{31}$ Conferencia, Mensaje, 1972, p. 5. ${ }^{32}$ Ibid. educar. Así, estas circunstancias son un clemento más en el juicio que los matrimonios hagan, tanto sobre el número de hijos como sobre los medios para lograrlo. ${ }^{33}$

Como los documentos anteriores, el del episcopado mexicano se aleja del dogma institucional tradicional para pasar a conformar una propuesta religiosa en torno a la familia de acuerdo con una realidad más específica. Ese vínculo hace posible una Iglesia más social, en cuanto que el ser humano tiene la opción de elcgir según sus condiciones económicosociales. Hay, en todo caso, una libertad que le crea también la posibiliclad de tener más adeptos. Es un discurso episcopal bastante sugerente, pues busca que el creyente se acerque más a la religión, considerando sus intereses antes que los de la institución religiosa. Al hacerlo de este modo, se convierte en un discurso que rebasa las ideas del discurso episcopal vaticano y que, como quiera que sea, se ve menos beligerante. ${ }^{3 i}$

\section{NOTA FINAI.}

Las categorías propuestas en estc estudio pueden funcionar como una

${ }^{33}$ Ibid., p. 7.

${ }^{34} \mathrm{Sin}$ querer -0 tal vez intencionalmente- el discurso desarrollado en este Mensaje estaba mís cerca de lo que meses antes, en abril de 1972, propusieron los Cristianos por el Socialismo en Santiago de Chile: una desideologización del cristianismo, una depuración frente al capitalismo, aspecto, este último, que no se ve totalmente en el discurso episcopal del Vaticano. 
herramienta de análisis factible, pues permiten tener una idea más precisa de los lineamientos temáticos que se proponen en la Iglesia como institución. Son, de otra manera, una opción posible desde la cual la religión, el fenómeno religioso, puede ser estudiado descle otros puntos de vista. Así, la importancia de esas categorías radica en el hecho de que se vislumbra mejor la fuerza de los dos discursos principales, el bíblico y el episcopal. Atendiendo a éstos, el historiador puede construir sus reflexiones tanto alrededor del discurso escrito como del no escrito, logrando así una percepción diferente y, hasta cierto punto, novedosa.

Según lo anterior, en este ensayo se intentó destacar la idea de familia propuesta en los años 60. Ello con el fin de precisar el cambio sutil que, acerca de las ideas en torno al aspecto demográfico, se realizó en el Concilio Vaticano II, tomó fuerza en la Segunda Conferencia General del Episcopado Latinoamericano por las condiciones sociales de América Latina y fue presentado, de manera específica por el episcopado mexicano, como ejemplo en el Mensaje del episcopado al pueblo de México.

Evidentemente, lo expuesto aquí son sólo señalamientos a una problemática mucho más profunda, sobre todo si se considera desde la situación actual, ya que todo lo relacionado con la familia ha tenido respuestas diferentes desde el inicio del pontificado de Juan Pablo II; pero ello únicamente puede percibirse tomando como precedentes el Concilio Vaticano II, la Segunda Conferencia General del Episcopado Latinoamericano y lo realizado por el episcopado mexicano de hace más de veinte años. En este aspecto, al reunir esas ideas se entiende el proceso por el que está pasando el discurso episcopal procedente del Vaticano, el cual no asume las nuevas condiciones histórico-sociales del mundo, ni de Latinoamérica en particular, sino estos precedentes. Finalmente, considero que la Iglesia católica, como institución, se encuentra en un momento de desfase frente a la realidad en que le toca vivir. Esto se evidencia al considerar la pluralidad discursiva sobre los diferentes aspectos temáticos trascendentes, como el de la familia por ejemplo, que han sido desarrollados a lo largo clel tiempo por la Iglesia católica. Quede, pues, este escrito como una primera aproximación al complejo proceso religioso católico.

\section{BIBLIOGRAFÍA}

-Benveniste, Emile, Problemas de lingüistica general, trad. Juan Almela, Siglo XXI, México, 1985, 12a ed., t. I.

-Blancarte, Roberto, Historia de la Iglesia católica en México, 1929-1982, FCE/EI Colegio Mexiquense, México, 1993, 2a. ed.

-Cervantes Blengio, Carlos, ¿Qué es la Teología de la Liberación Latinoamericana?, Editora de Revistas, México, 1989, 2a. ed.

-Concilio Vaticano II, Documentos completos, Librería Parroquial, México, 1995, 17a. ed.

-Conferencia del Episcopado Mexicano, Documentos colectivos del Eptscopado Mexicano. A diez años del Concilio Vaticano II, Comisión Episcopal de Medios de Comunicación Social, México, 1991, 3a. ed. 
Mensaje del Episcopado al pueblo de México sobre la paternidad responsable, Librería Parroquial, México, 1972.

-Connaughton, Brian F. y Andrés Lira González, Las fuentes eclesiásticas para la bistoria social de México, UAM/Instituto Mora, México, 1996.

-Dussel, Enrique, "Palabras preliminares" en Historia general de la Iglesia en América Latina, CEHILA/Eds. Sígueme/ Eds. Paulinas, México, 1984.

-Engels, Feclerico, "El origen de la familia, la propiedad privada y el Estado" en Carlos Marx y Federico Engels, Obras escogidas, Editorial Progreso, Moscú, 1986 , t. III.

-Fábrega Escatllar, Valentín, La berejía vaticana, Siglo XXI, Madrid, 1996.

-Frye, Northrop, El gran código. Una lectura mitológica y literaria de la Biblia, trad. Elizabeth Casals, Gedisa, Barcelona, 1988.

-Gonzalbo Aizpuru, Pilar, "En busca de las familias novohispanas" en Connaughton y Lira González, Fuentes, 1996, pp. 177-189.

-Gutiérrez Casillas, José, Historia de la Iglesia en México, Porrúa, México, 1993, 3a. ed. rev.

-Guzmán García, Luis, "Relaciones Iglesia-Estado" en Tendencias eclesiásticas y crisis en los años ochenta, CIESAS, México, 1990.

-Iglesia y religiosidad, introd. y selec. de Pilar Gonzalbo Aizpuru, El Colegio de México, México, 1992.

-Jitrik, Noé, El balcón barroco, UNAM, México, 1988.

-Juan Pablo II, El evangelio de la vida, Eds. Paulinas, México, 1995.
-Jung, Carl G., Psicología y simbólica del arquetipo, Paidós, Barcelona, 1992 (Psicología profunda, 29).

-Leach, Edmund, Cultura y comunicación. La lógica de la conexión de los símbolos. Una introducción al uso del análisis estructural en la antropologia social, Siglo XXI, Madrid, 1978.

-Loaeza Tovar, Soledad, El fin de la ambigüedad: las relaciones entre la Iglesia y el Estado en México, 1982-1989, IMDOSOC, México, 1990.

-Marroquín, Enrique, "El discurso religioso" en La iglesia y el poder. Reflexiones sociológicas sobre la Iglesia, lids. Dabar, México, 1993.

-Masferrer Kan, Elio, "Nuevos movimientos y tendencias religiosas en América Latina", Religiones: cuestiones teórico-metodológicas, núm. 1, enero-junio, 1991, pp. 43-56.

-Meslin, Michel, Aproximación a una ciencia de las religiones, Ediciones Cristiandad, Madrid, 1978.

-Puente de Guzmán, María Alicia, Papel $y$ responsabilidad social de los lai-cos. "Rerum Novarum", derechos bumanos $y$ derechos sociales, IMDOSOC, México, 1991.

-Puente Lutteroth, María Alicia (comp.), Hacia una bistoria minima de la Iglesia en México, Jus/CeHils, México, 1993.

-Segunda Conferencia General del Episcopado Latinoamericano, La Iglesia en la actual transformación de América Latina a la luz del Concilio II. Conclusiones, Librería Parroquial, México, 1968.

-Suess, Paulo, "La historia de los Otros escrita por nosotros. Apuntes para una autocrítica de la historiografía del cristianismo en América Latina", Boletín CKHLA, núms. 47-48, marzo de 1994, pp. 1-10. 


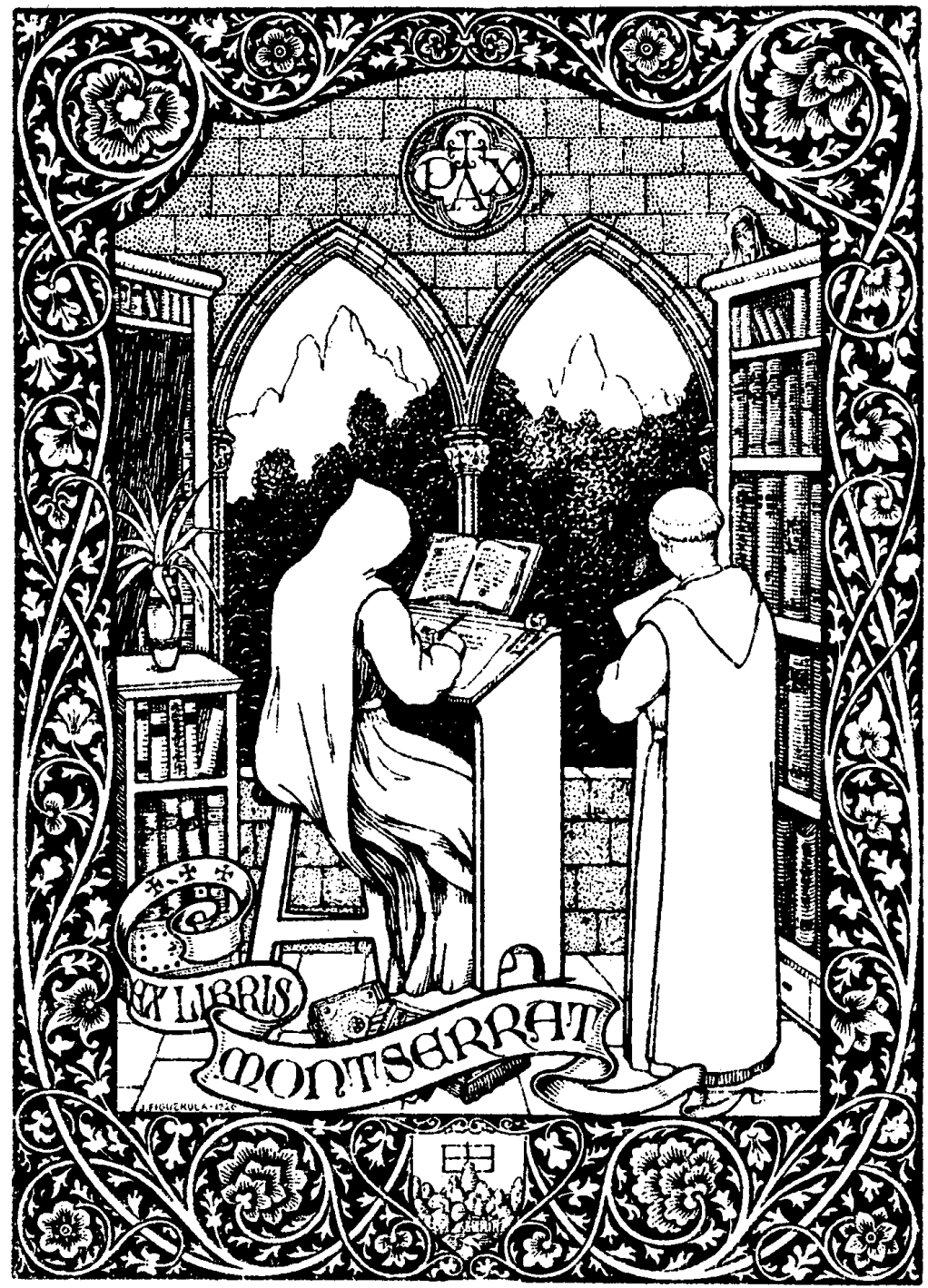

